\title{
Using treated wastewater as a potential solution of water scarcity and mitigation measure of climate change in Gaza strip
}

\author{
Eng. Jamal Y. Al-Dadah \\ M.Sc. in Agriculture \& Environmental Science, Head of Planning Department, Palestinian water Authority, Gaza Strip
}

Email address:

jaldadah@hotmail.com

\section{To cite this article:}

Eng. Jamal Y. Al-Dadah. Using Treated Wastewater as a Potential Solution of Water Scarcity and Mitigation Measure of Climate Change in Gaza Strip. Journal of Water Resources and Ocean Science. Vol. 2, No. 5, 2013, pp. 79-83. doi: 10.11648/j.wros.20130205.14

\begin{abstract}
The use of wastewater is one of the most sustainable alternatives to cope with water shortage in Gaza Strip (GS). It would have a number of advantages that include closing the gap between supply and demand, alleviating the pollution of fresh water resources, providing sound solution to water scarcity and potentially cover half of the total agricultural water demand in GS. Wastewater reuse could provide a mitigation solution to climate change through the reduction in green house gases by using less energy for wastewater management compared to that for importing water, pumping deep groundwater, seawater desalination, or exporting wastewater, and enrich the deteriorated soils in GS with more organic matter which lowering the application of chemical fertilizers. This paper investigated the effects of wastewater application on the level of organic matter and soil carbon sequestration which demonstrated by many experiments in Gaza Strip, which induced the possibility of wastewater as a mitigation measure of climate change.
\end{abstract}

Keywords: Wastewater, Water Scarcity, Mitigation, Gaza Strip, Water Shortage, Integrated Water Management Plan, Climate Change, Wastewater Reuse

\section{Introduction}

The combination of severe water shortage, contamination of water resources, densely populated area and highly intensive irrigated agriculture characterizedGaza Stripwhich described as one of the most exploited places in the world where the level of demand on water and land resources exceed the capacity of the environment. The water balance records revealed a water deficit of $80 \mathrm{MCM}$ in 2012 ( Palestinian Water Authority, 2012).Climate change is expected to aggravate the situation even more. Wastewater effluent is the most readily available and cheapest source of additional water and provides a partial solution to the water scarcity problem. The agriculture sector is the second major consumer of groundwater in the Gaza Strip, where the level of groundwater, the main water resource, is being depleted and its quality is adversely affected. Irrigated agriculture plays a noticeable role in the sustainability of crop production to feed the rapid increasing population in the Gaza Strip.The total abstraction of ground water as estimated is proximately 181 $\mathrm{MCM} / \mathrm{y}$, from which $95 \mathrm{MCM} / \mathrm{y}$ for domestic use $(90$
$\mathrm{MCM} / \mathrm{y}$ from Gaza water wells and about $5 \mathrm{MCM} / \mathrm{y}$ from Mekorot, Israeli Water Company ), (CSO-G, 2011), while the total water supplied for agriculture use was about 86 $\mathrm{MCM} / \mathrm{y}$. This over extraction from the aquifer has resulted in drawdown of the groundwater with resulting intrusion of seawater and up-coning the underlying saline water. As a result of all current and expected problems, there is an urgent need to adopt solutions to achieve conservation of water quantity, improve water quality, and achieve sustainability. Selected solutions may be one or more of the following: i) Water use conservation, ii) Desalination of sea water, iii) Storm water collection, iv) treated waste water (TWW) for agricultural uses. Palestinian Water Authority (PWA) reported a range of conclusions as to the required future interventions in the water sector. The first conclusion pertains to the existing situation in relation to water supply in Gaza, with strong rejection the continuation of the "status quo" as an acceptable option. This reflects the fact that the groundwater which is the only source of fresh water in Gaza at the present time is being massively overpumped and the aquifer is showing clear signs of imminent failure or collapse, with rapidly advancing degradation of the water resources in terms of quality and quantity as 
shown in Figure 1. Severe contamination mainly from disposing raw or partially wastewater to the sea or adjacent water coursesis also evident, and almost none of the groundwater meets internationally accepted guidelines for use as a domestic supply. The population of approximately 1.7 million Palestinians in Gaza, (PWA, 2012) is therefore exposed to very high levels of risk and high levels of waterborne disease continue to be prevalent amongst the Gaza population.

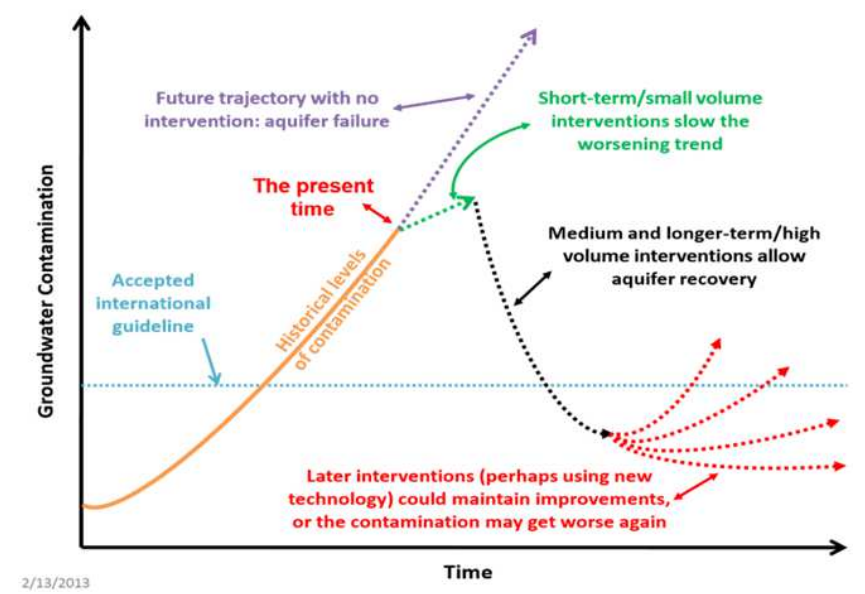

Figure 1. Problems relating to the groundwater in Gaza Strip

\section{Integrated Water Management Plan in GS}

Wastewater is becoming a common source for additional water in some water scarce regions and many countries have included wastewater re-use in their water planning. Water demand in the GS is increasing continuously due to economic development and population increase resulting from natural growth and returnees, while the water resources are constant or even decreasing due to urban development. The use of wastewater as a supplemental source of irrigation is inevitable for increased agricultural production in Gaza where irrigation supplies are insufficient to meet crop water needs. Moreover, irrigation with treated waste water is considered a promising practice that helps in minimizing the pollution of the ecosystem subjected to contamination by direct disposal of wastewater (WW)into surface or ground water. In addition, ww is a valuable source for plant nutrients and organic matter needed for maintaining fertility and productivity of arid soils. However, reuse of waste water for irrigation may potentially create environmental problems if not properly treated and managed. It is stated in the National Water Plan (NWP) that wastewater investment costs represents about $37 \%$ of the overall Palestinian investment plan for Gaza Strip overall the period time to achieve the strategies and targets outlined in the National Water Plan. The national investment target for wastewater production was set for from a careful consideration of the extent of the sewerage works, and the construction of the wastewater treatment plants. Wastewater reuse schemes are indispensable option for Palestine in general and Gaza in particular. The Integrated Aquifer Management Program (IAMP) aims to reduce the agricultural pumping from $90 \mathrm{MCM}$ per year to about 50-60 MCM per year. The difference between these two volumes could be supplied by reclaimed water directly from the three regional treatment plants and a small quantity may be extracted from recovery wells in the vicinity of proposed infiltration basins as illustrated in Figure 2.

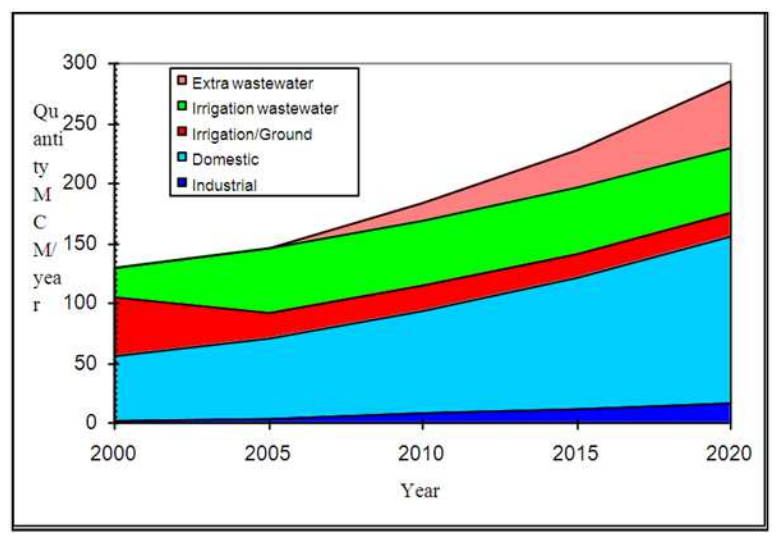

Figure 2. Planned Utilization of Wastewater in Gaza Strip

\section{Potential and Perspective of Wastewater Reuse in Gaza Strip}

Wastewater generation is around $80 \%$ of water use for domestic purposes. The quantities of treated wastewater are expected to reach $180 \mathrm{MCM}$ per year by 2025. This quantity is a good potential to minimize the shortage in water sources in the area. The quality of raw wastewater is considered acceptable for reuse after treatment according to the design criteria of the WWTPs. Effluent is available throughout the year at a fairly constant flow whilst water demand from crops will vary. Demand in winter will be small as the rainfall is marginally sufficient to meet the water demands of all crops. The complexity of attempting to supply effluent in winter is great as demand would fluctuate widely according to the rainfall. The maximum area that can be irrigated by treated wastewater depends on many factors like the distribution of crop patterns, land tenure and on the peak demand of the mix of crops and the flow available at this time. It can be seen that peak monthly water demand for crops occurs in April to extended to September in some cases . Accordingly, the maximum quantity of treated effluent may be used in Gaza Strip -in case of accounting for all the fruits areas ( Citrus, Olives and other Fruit Trees)and converting the rain-fed areas to irrigated areas partially , maximally, the quantity of effluent will be used is about35-40 MCM/year. However, the total needs of the entiretreated effluent is subject to more augmentation in case of climate change impacts and additions of leaching fractions due to the high water salinity. The areas of land that could be irrigated to satisfy peak 
demand with the effluent flow available during these periods are demonstrated in the table (1).

Table 1. Distribution and Potential Areas of WW reuse in GS. Crops Total area, Dunam Water Quota/dunam Total Water Demand Potential of WW Reuse MCM/Area

\begin{tabular}{c|cccc}
\hline Citrus & 15,000 & 1000 & 15 & Yes \\
Olive & 25,000 & 400 & 10 & Yes \\
Fruits & 28600 & 500 & 14.3 & Partially \\
Field crops & 40470 & $100-400$ & 5 & Flag \\
Vegetables & 61000 & 700 & 42 & Excluded \\
Total & 170,448 & & & $35-40$ MCM \\
\hline
\end{tabular}

In the Gaza Strip, pilot wastewater reuse schemes have existed for some years, and there are plans for these to be augmented shortly. The key requirement, however, is for the completion of the four major wastewater treatment plants scattered throughout Gaza, as reuse cannot be introduced at any significant scale in the absence of highquality wastewater treatment.

The amount of collected, treated wastewater, and that will be reused in the future is a matter of great concernin Gaza Strip and tobe expected to increase substantially with population growth, rapid urbanization, and improvement of sanitation service coverage. But, on the other hand, wastewater utilization should be managed within certain restrictions imposed for environmental protection and to safeguard public health. Availability and utilization of treated wastewater constitutes one of the most factors considered regarding the expansion in irrigated agriculture and the associated agricultural water demand. However, is for the completion of the four major wastewater treatment plants throughout Gaza, as reuse cannot be introduced at any significant scale in the absence of high-quality wastewater treatment as shown in Figure 3.

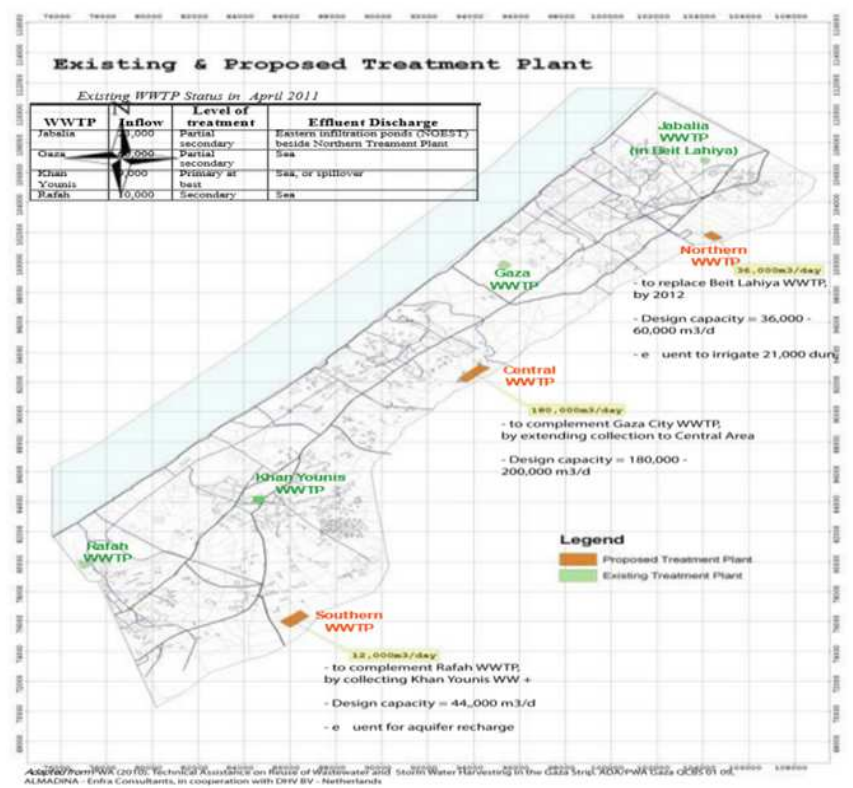

Figure 3. Planned Wastewater Treatment Plants and reuse schemes in GS

\section{Interaction between Wastewater Reuse and Climate Change}

Climate change is the rise in temperature, is a natural phenomenon that takes place in nature as a result of the release of greenhouse gases (water vapor, carbon dioxide $\left(\mathrm{CO}_{2}\right)$, and other NOx gases). Due to the fact that human industrial activities have increased in recent centuries, $\mathrm{CO}_{2}$ gas emissions and other greenhouse gases have risen dramatically. According to the estimates of the International Panel on Climate Change, the (IPCC), the Middle Eastregion and North Africa will be the region most severely affected by climate change in the coming decades.

Soil carbon sequestration will be an important mitigation strategy to reduce atmospheric $\mathrm{CO}_{2}$ concentrations. The process of transferring atmospheric $\mathrm{CO}_{2}$ into soil and biotic pools can enhance soil quality, increase agronomic productivity, improve quality of natural waters, and lower rates of anoxia (decrease in the level of oxygen) or hypoxia (dead water) in coastal ecosystems. Soil carbon sequestration is enhanced through agricultural management practices (such as increased application of organic manures, use of intercrops and green manures, higher shares of perennial grasslands and trees or hedges, etc.), which promote greater soil organic matter (and thus soil organic carbon) content and improve soil structure (see, e.g., Niggli et al. 2008; ).Increasing soil organic carbon in agricultural systems has also been pointed out as an important mitigation option by IPCC (2007b). Very rough estimates for the global mitigation potential of Organic matteramount to 3.5-4.8 $\mathrm{GtCO}_{2}$ from carbon sequestration (around 55-80 percent of total global greenhouse gas emissions from agriculture) and a reduction of $\mathrm{NO}_{2}$ by two-thirds (Niggli et al. 2008). For sound estimates, however, more information on the mitigation potential of $\mathrm{OM}$ duly differentiated according to climatic zones, local climatic conditions, soil characteristics, variations in crops and cultivation practices, etc.- is still needed.Two Field experiments wereconductedin South of GS to evaluate the short term effect of irrigation with treated wastewater on the level of soil Organic Matter (OM) and accumulation of heavy metals in the upper soil layer and plants. Soil organic content (OM) significantly increased with wastewater irrigation application and with increasing the period of application which is attributed directly to the contents of the nutrients and organic compounds in the wastewater applied. The soil OM contents accumulated more in the topsoil in all treatments. This increase was the highest in the top soil $(0-20 \mathrm{~cm})$ and for the longer period of wastewater application. Several researchers reported accumulation of $\mathrm{N}$, $\mathrm{P}$, and $\mathrm{K}$ in the soil with wastewater application which was attributed to the original contents of these nutrients in the wastewater applied O.M\% tends to decrease after irrigation by well water, while the opposite trend was obtained with irrigation by treated wastewater as shown in Figure4. This is due to high nutrients result in rich biomass production, showing a benefit to the soil. Because of the soil's organic 
substance, physical and chemical properties improved. This enabled granular structures to form, and crop growth accelerated and enjoyed nutrient absorption (Wang \& Wang, 2005). OM as a mitigation strategy addresses both emissions avoidance and carbon sequestration. It is achieved through:

- lower $\mathrm{N} 2 \mathrm{O}$ emissions (due to lower nitrogen input) - it is usually assumed that $1-2$ percent of the nitrogen applied to farming systems is emitted as $\mathrm{N} 2 \mathrm{O}$, irrespective of the form of the nitrogen input. The default value currently used by the IPCC is 1.25 percent, but newer research finds considerably lower values, such as for semi-arid areas [e.g., Barton et al. 2008];

- less CO2 emissions through erosion (due to better soil structure and more plantcover).

- lower $\mathrm{CO}_{2}$ emissions from farming system inputs (pesticides and fertilizers produced using fossil fuel).

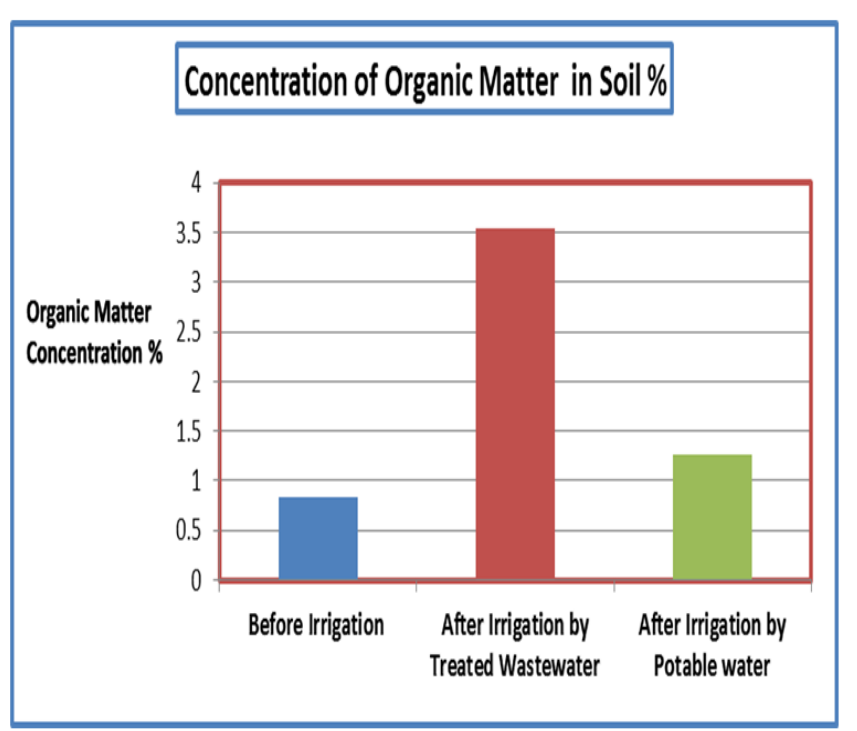

Figure 4. Concentration of Organic Matter in Soil (\%)

\section{Wastewater Reuse and Drought Mitigation}

In arid and semi-arid countries, particularly the developing ones, the full utilization and re-use of sewage water is still far from our final goal, i.e. to be used as a water source, in spite of the vital role it could play in reducing the high pressure imposed on the limited available freshwater. Health and environmental problems are the major obstacles restricting the sustainable and safe reuse and recycle of wastewater which require concerted efforts supported by regional and international organizations. Treated water may be substituted for conventional resources and itmay be reused for purposes such as nonagricultural irrigation (parks, green areas, jungles and deserts,$\ldots$ etc.), and when rainfall is insufficient to meet the increasing needs to feed the future generation.

\section{Conclusion}

The obvious conclusion and the initial results of the current pilot projects carried out in GS emphasized that a high degree of effluent reuse must be achieved in Gaza in order to reduce the current levels of groundwater withdrawal by the agricultural sector and mitigate the negative environmentally sound impacts. All future collection and treatment strategies should integrate reuse possibilities wherever practical. Reuse of wastewater effluent offers the he release of complementary resources, sustaining the existing and expanding irrigated areas, in addition to the treated wastewater provides a renewable and valuable source for agriculture and free limited water supplies for domestic and industrial purposes. Reuse of sewage water when properly managed, has the benefit of reducing environmental degradation as well as mitigation measure of climate change.

\section{Acknowledgement}

The author would like to express his gratitude for PWA, particularly Eng. RebhiAlSheikh, Deputy Chairman-PWA, forhis ever supporting and high appreciation and thanks for International Center ofAgricultural Research in Dry Areas (ICARDA)Amman, Jordanfor theirsupervision , finance and sponsorship for the WW reuse projects in GS.

\section{References}

[1] Abu Nada, Z. M. , 2009 . Long Term Impact of Wastewater Irrigation on Soil and Crop Quality Parameters in Gaza Strip. Islamic University. M.Sc degree thesis.

[2] AL-Sbaihi,H .Abu Sharekh, Y.,Akelane , S. , 2013.Short Term Effect of Wastewater Reuse on the level of Organic Matter and Accumulation of Heavy Metals on Soil and Zea mays (Corn)in Al-Zaitoun District - Gaza Strip.

[3] Barton, L., R. Kiese, D. Gatter, K. Butterbach-Bahl, R. Buck, C. Hinz, and D. Murphy. 2008. "Nitrous Oxide Emissions from a Cropped Soil in a Semi-arid Climate," Global ChangeBiology 14: 177-92.

[4] Climate Change and Food Security: A Framework Document. Rome:FAO/WHO (Food and Agriculture Organization/World Health Organization).

[5] French Regional Mission for water and agriculture (MREA), 2004. Partial Results for the season 2003, Technical Report.

[6] IPCC. 2007a. "Summary for Policy Makers." In IPCC Fourth Assessment Report, "Working Group II Report: Impacts, Adaptation, and Vulnerability." See specifically onadaptation, chapter 17; on inter-relationships between adaptation and mitigation, chapter

[7] KFW, Kreditanstalt fur Wiederaufbau, Sludge and Effluent Reuse Study for Gaza Central Area, February, 2006.

[8] Metcalf \& Eddy. 1991. Wastewater Engineering: Treatment, Disposal and Reuse. New York; McGraw- Hillel Inc. 
[9] Ministry of Agriculture. 2011. Annual Data Report.

[10] Palestinian Central Bureau of Statistics (2007): Population, housing and establishment census 2007, Palestinian National Authority.

[11] Palestinian Water Authority (2001): Coastal Aquifer Management Program (CAMP), Integrated Aquifer Management Plan (Task 25), Gaza.
[12] Palestinian Water authority, 2011. Comparative Study of Option for additional water supply in GS (CSO-G, 2011).

[13] World Bank, 2004. West Bank and Gaza Wastewater Treatment and Reuse Policy Note. Water \& Environment Department, the Middle East and North Africa Region. 